\title{
Music Therapy in Traditional African Societies: Origin, Basis and Application in Nigeria
}

\author{
Charles O. Aluede \\ Department of Theater Arts, Ambrose Alli University, Ekpoma, Edo State, Nigeria
}

KEYWORDS Music Therapy. Music Therapist. Faith Healer. Herbalist

ABSTRACT The use of music in healing and healing rites in African traditional societies is as old as the origin of African Continent. This paper attempted a historical origin of this art, provides a theoretical basis for Music Therapy in Africa and concludes by specifically highlighting areas where the use of Music Therapy has yielded fruitful results in Nigeria.

\section{INTRODUCTION}

An examination of the functions of traditional African music in African societies reveals that music is woven around every event of the Africans life from birth through to death. Abinitio African music scholars have in great depth discussed music and its state in Africa. However, there appears to be an alarming paucity of records on the healing properties of African music. This development has generated questions like, is music therapy a very new phenomenon in African culture? How old is music therapy in Africa? Has music therapy in Africa any theoretical basis? Who is a music therapist in Africa? And what kind of training does a music therapist undergo in Africa?

While this paper will attempt to provide answers to the myriad of questions raised in the above paragraph, it should be preemptively registered that because certain skills in Africa are daily exercised in ordinary contexts, little or no importance is therefore attached thus usually overlooked and musical skill is one.

\section{MUSIC THERAPY}

\section{What is Music Therapy?}

Structurally speaking, music therapy is a compound word which requires separate treatments for the sake of clarity. Patrick (1972) observes that music is one of the fine arts which is concerned with the combination of sounds with a view of beauty of form and the expression of thought or feeling. To Dickens (1969), therapy is derived from a Greek verb Therapeuim and its noun therapeia. In his view, therapeuim means "to take care of" while Therapeia means "service and treatment". He opines further by saying that the word heal has various derivations all meaning whole. He further observes that not one of us is really whole; we all need help to find and fulfill ourselves. Music therapy can therefore be defined as the art of using musical sounds in bringing changes from undesirable unhealthy conditions to a more comfortable one in a person's life.

\section{The Origin of Music Therapy in Africa}

Exactly when and how music began in traditional African societies remains a puzzle till today. In a report on music in West Africa, southern writes:

It is impossible to know all of the facts about the music of the past in West Africa because of the lack of indigenous written records. We can learn a great deal however, from two major sources of historical information: the old traditions of the land and the books written by European travelers and traders (Southern 1971: 4).

The two historical information sources also had their demerits. While the indigenes could not document their musical genre as a result of the non-literate/oral circumstance they found themselves, the European travelers simply had primary economic motif. More than this, the traders not being ethnomusicologists could not have done any indepth documentation. Apart from these factors, early Western musicologists owned up their incompetence to study and analyze this music hence Bukofzer (1957), concludes that a historical study of non western music is at present an unattainable goal as it lacks the kind of historical documents they are used to in their normal research.

Gouldron (1968), says it is doubtful that we 
shall ever know when and under what circumstances the first musical utterance was made, yet every culture developed some form of musical tradition and many of them possessed legends. Farmer (1957) says a clay ocarina with five holes portrays already flourishing music as early as 10,000 BC. However, our earliest civilizations have been estimated to have been established no more than 8,000 years ago. The African continent is made up of autonomous groups who have incredible wealth of myths legends about the origins of their musical genres. In the opinion of McClellan (1988: 1), "Almost all these legends attribute a divine origin to music, in no case was music said to be invented by humans. In the world's mythologies music was either discovered or was bestowed on us by super natural beings". Although for paucity of records, the origin of music in Africa is unknown, it is non-controvertible that world civilization started from Mesopotamia and Africa - Egypt precisely speaking. Music therapy without doubt, may have evolved in about the same era.

To Bacharach (1977: 25), “Ancient Egyptian civilization is nearly as old as Mesopotamian, and there was probably some contact between the two well before 2500 B. C., since at that time they had many instruments in common, the Egyptian instruments were at an earlier stage of development". In a similar view, Miller (1960:4) says "Egyptian music was very likely quite extensive. It had considerable influence upon later Greek music and musical theory of the $7^{\text {th }}$ century BC." He stresses further by saying that they were responsible for the development of the harp and Lyre family of instruments. Muir (1980) posits that the world's first keyboard instrument was the organ. It was made around the third century B. C. by a well-known Egyptian inventor and barber, Ctesibius. These invented musical instruments were not just for entertainment, sending war signals and praising gods because healing through music was a major function. To this end, Koizumi (II 72025) notes that "in the Ancient Kingdoms of Assyria, Babylonia, Sumeria and Egypt, musicians were priests who calculated the calendar and astrological measurements of the heavenly bodies, supervised ceremonies and cured the sick". Although in this paper it is being attempted to suggest that music therapy may have started from Egypt based on her early civilization beliefs, their quality of music is lost as the carving and paintings on the walls and tombs simply reveal certain musical instruments used in some periods without any form of musical notation or documentation. Where ever music therapy may have first originated, one fact that is clear is that this practice in found in all African States. Can music actually heal? To this kind of question, Randall McClellan observes:

... Music affect our individual bodies through the principle of resonance, but music's primary advantage is that it works with the personal (emotional) level as well as the transpersonal (spiritual) level. The basic premise upon which healing through music operates is that a primary cause of disease is emotional stress and negative mental attitudes that create energy imbalances and blockages (McClellan 1988: 109).

\section{The Theoretical Basis of Music Therapy in Africa}

All over the world, the Bible as well as other great books of historical and revealed religious knowledge potray general agreement on the efficacious use of musical sounds in healings. According to Paul Twichell, one time Eckankar living master, the $\mathrm{Hu}$ sound pronounced (Hiu) rules the entire universe. In his view, a moving engine, the over all sound from transactions in the market, sounds of water falls and oceans have that $\mathrm{Hu}$ sound of life. Thus $\mathrm{Hu}$ sound heals, rejuvenates and enlivens who ever sings it. In a similar style, Swami Rama (1978) talks of Hindu Swamis as being able to discard their bodies (Soul/Astral traveling) and even performing healings by chanting Aum. Supporting the above view, Swami Prabhupada (1991) says in Krsna consciousness, chanting can be done - two ways: real chanting or singing the mantra called Kirtana and that the martras if devotedly sung makes the singer achieve physical and spiritual purity.

Rama (1978) and Prabhupada (1991) are for sure not alone in this opinion Dom Cyril vonkrasinki et al in Mitchell declare that music is considered a vital source of spiritual transformation, and vibrations are recognized as cosmic manifestations of a spiritual principle. The lamas (of Tibet) have developed a science as well as an art of sound. They carefully cultivate sensitivity to musical pitch and tone and the moods thereby created they believe have the power to heal or if mis-used, can cause illness, according to the vibrations involved (Mitchell Elsie, 1980: 12). 
In 1 Samuel chapter 17 verse 10, the Holy Bible gives a vivid account of how David played the lyre to cure King Saul of his mental problem it was said that God sent evil spirits upon him. This statement is further corroborated when on this issue Sendry (1974: 24) said “... in the old testament King Saul's insanity was cured over night by the power of David's harp".

The curative properties of music is not just known in the religious circles alone. In the ordinary social lives of the Africans this belief is held and explored but what amazes one who is research minded is the rarity of documented facts to rely upon. This present paucity of materials is obviously hinged on the fact that until very recently, records in African societies were orally kept. However, discussing music of Ancient Egypt, Farmer (1957) says the Egyptians performed music for its aesthetic beauty and its spiritual meanings. While Theophrastus (370288BC) observed that "the sound of a flute will cure epilepsy and a sciatic gut", Coelius Antipater (121BC) said "pain is relieved by causing a vibration in the fibres of the afflicted part". Examining the situation in Nigeria, Lateef (1987: 199) posits that "Long before the mid - 1940's, when for the first time in the USA music therapy began to be used as a specialty, music therapy was one of the major aspects of the Bori religion in Nigeria". In African societies there are many pointers which indicate their firm belief in and practice of music therapy. A major one of such is that music can be used to revive a dying person or animal. In African States, there is this notion that a dying person needs absolute silence (perfectly peaceful atmosphere) to expire. The belief is that the process through which the soul detaches from the body is cumbersome and requires quiet moments. To resuscitate a dying person, a single tone of wind instrument is sounded into the person's ears. For little chicks and other birds, a bowl is turned up side down encircling the animal while a healing song with intense drumming on the bowl is carried out. This practice has quite often yielded results.

Just a note to end this segment, it means Africans are certain about the healing nature of musical sound and this idea has been in existence long before now because in their belief the mind rules the body hence Gotlib (1988: 134) opines: "Only in the 1970s and 1980s did it become widely accepted that illness results from a combination of both physical and psychological causes (in America)".

\section{Who is a Music Therapist in African Traditional Society?}

The vulnerability of traditional African music remains the primary reason for its collective ownership this is of cause why there is no distinction between audience and performers in Africa. This art is of many shades and so the practitioners of this kind of therapy are also of different types and they are:

$i$. Herbalists: These are traditional people who are skilled in the use of herbs and animal parts to treat human ailments. In Nigeria these herbalists are purely traditional healers and not native or witch doctors. They do not consult oracle. They are simply known as herbalists. As consultant healers, they know when music can curatively be applied to patients' situation. Other forms of therapy used by such practitioners include, blood letting, Heat therapy, Hydro - therapy, Massage etc.

ii. Native/Witch Doctors: These are people of super physical powers who can read the oracle and also understand the mysteries of the coven and necromantic assembly. The native doctors in Nigeria have special drums made of the hide of Indian pythons. These drums are usually consecrated before use. The native doctors believe that wicked deeds such as taking part in the spiritual attack of relations, having evil hands in relations' business can make one develop guilty conscience that can manifest in emotional sickness. When the drum is played for them to dance to, they are moved to confess their misdeeds and are therefore relieved of their burden and completely healed. Music therapy in the nationalities of Nigeria has remained efficacious till date because music has been identified to work on the emotional and spiritual levels in a man's mind. In this vein, Sufi, Inayat Khan in McClellan (1988: 109) posits that "the existence of illness in the body may be called a shadow of the true illness which is held by man in his mind".

iii. Faith Healers: Mume (1973) talks of faith healing in Nigeria as being a medicoreligious practice. He gives an example of such as "Igbeuku" - a sect found in Delta 
Nigeria. Its parallel is the "Iyayi Cult" of the Esan in Edo state, Nigeria. He posits further that:

In the practice of religious Igbeuku, patients are persuaded to confess their sins which torture them, and once this is done, such patients feel emotionally relieved after the priest has pronounced them clean and subjected them to rigorous dancing exercise (Mume, 1973: 62).

Mume's book from where the quotation above was excerpted has its caption as traditional medicine in Nigeria and so cannot be completely blamed for talking about dance without addressing music. During the field trips which culminated into this work, it was discovered that confession of sins was done amidst singing, drumming and dancing.

iv. Soothing Music: In the course of this research, it was discovered that not much has been written about what goes on during male and female circumcision, bone setting, traditional surgery and blood letting exercises. In Nigeria, during the above mentioned events, music is copiously made to reduce the pains associated with the surgical treatment being administered. The texts of the music in this realm is usually perseverance and endurance to enable good result be achieved.

In all, all the musicians talked about in this segment go through one prescribed course of training or the other. the training techniques can be summarized under apprientiship system with role imitation, rhythmic memorization, dramatic sketches, voice training and care giving as core courses.

\section{Application of Music Therapy in Nigeria}

The use of music in the healing of sickness in Nigeria has a scope. Not all disorders require music therapy, hence other areas previously mentioned in this work. music as a curative agent is primarily used in the treatment of psychological and emotionally induced disorders.

The Major Realms Where Music Therapy has Proved Very Successful in Nigeria are:

1. During death of family members and reviving a patient in coma

2. Healing patients tormented by spirits and faith healing by traditional religious groups
3. Healing patients of general debilities through music and dance.

1. Death of Family Members and Reviving Patients in Coma: The death of a family member is always a wound in one's heart. The natural reactions associated with such news are initial shock; disbelief; denial; emotional numbness; guilt feelings; anger. - (watch tower Bibbe and tract society 2000) expounding this issue further, they posited that:

Acute grief may include: memory loss and Insomnia, extreme fatigue, abrupt changes of mood, flawed judgment and thinking; bouts of crying; appetite changes, with resultant weight loss or gain: a variety of symptoms of disturbed health, lethargy; reduced work capacity; (2000: 9)

The moody situation caused by death is usually dispelled by music. This kind of music though dirges are very philosophical as it talks of life and describes this present world as a market place where people meet and retire to there abodes. Such songs also talk of hades as the final resting place for all mortals.

Akin to this situations music is also used as a reviving agent for a dying person or one in coma. As a common practice generally in Nigeria and the Esan of Edo State of Nigeria in particular, herbalists and native doctors have Oko - a small aerophone made of elephant tusk which is blown into dying patients' ears to resuscitate them. Exactly how this principle works is yet to be fully studied but Wallace in Russell (1998: 57) posits that "The human voice as a development is far in excess of anything that can be produced by natural selection. Monkeys have no music in their souls and no capacity for music in their vocal organs; where as even the lowest races of man have both". This is presumably why music does a lot of things to man.

2. Healing Patients Tormented by Spirits and Faith Healing by Traditional Religious Groups: Faith healing in Nigeria is purely a religious affair devoid of herbal treatment. This practice is found in the Bori cult of Northern Nigeria, the Igbeuku and Iyayi cults of Southern Nigeria to mention just a few. As held by Mume (1973: 75), "Nigerian faith healers are unlike the herbalists and the native doctors. While the later group employ herbal medication the former base their strength on religious prayer and confession 
of sins to release the mentally sick people from their low dejected emotional spirits which are responsible for their physical ailments". The faith healing has serious reliance on music which is a major vehicle in the healing processes.

3. Healing Patients of General Debilities Through Music and Dance: All over Nigeria, music and dance are principal to church services be it orthodox or syncrethic. The only point of difference is that while the use of dance in orthodox churches is with great finesse to eschew debased steps and mind drifting activities some employ rigorous traditional steps which have often led to frenzy and ecstatic states. The music and its associated dance in this setting has been discovered to be of immense value in the healing of ailments like dizziness, excess fat, Arthero sclerosis and coronary thrombosis, constipation and makes one sweat profusely and be duly exercised.

\section{IMPLICATION FOR PRACTICE}

While in some contexts the therapeutic process require the willing acceptance of the patient like in the case of Saul and David in the Holy Bible, in the traditional setting, there are dictatorial tendencies in the use of music by the native / witch doctors. However, faith healers use participatory management approach. This shows that the therapeutic process and the success in music therapy actually depend on the managerial traditions of the group the music therapists belong. Nevertheless, the tendency of the most traditional music therapists is to involve the patients seek their consent and make them participate in the process.

This shows that the democratic and participatory management approach needs to be emphasised and used in place of the laissez faire or dictatorial management approaches. The involvement of patients by the music therapists whether as faith healers, herbalists or witch doctors therefore needs greater attention than are presently applied.

\section{CONCLUSION}

This paper has been concerned with Music
Therapy in African Societies. It has examined its origin and theoretical basis drawing relevant accounts from the Bible and other related inspired books. The findings reveal that Music therapy in Nigeria has an age-old historical origin, which can be used in the treatment of emotional and psychological disorders effectively.

\section{REFERENCES}

Bukofzer, M.: The place of Musicology in American Institutions of Higher Learning. Liberal Arts Press, New York (1957).

Bacharach A.L.: The Musical Companion. Pan Book Ltd., London (1979).

Dickens, E.: Encyclopadia International. Vol. IV. Lexicon Publication Inc., New York (1969).

Farmer, H.: The music in ancient Egypt. In: The Oxford History of Music. Vol. 1, Egon Wellesz (Ed.). Oxford University Press, London (1957).

Frank Muir: The Frank Muir Book. Transworld Publishers Ltd., London (1980).

Gouldron, P.: Ancient and Oriental Music. Stuttman Co., New York (1968).

Gotlib, I. H.: New thinking about illness. In: Eye to Eye: How People Interact. Peter March (Ed.). Salem House Publishers, Massachusetts (1988).

Koizumi, F.: A Bell Ringing in an Egypt Sky. None such Records, New York (H-72025).

Lateef, Y.: Hausa performing Arts and Music. Lagos Federal Ministry of Information and Culture, Lagos (1987).

McClellan, R.: The Healing Forces of Music. Amity House Inc., New York (1988).

Mume, J. O.: Traditional Medicine in Nigeria. Jom Nature Cure Publishers, Agbarho (1973).

Mitchell, E.: Sun Buddhas, Moon Buddhas. M.A. John Weather hill Inc., Salem (1980).

Miller, H. M.: History of Music._ New York: Barnes and Noble Inc., New York (1960).

Patrick, D. Shorter Oxford English Dictionary. Oxford University Press, Oxford (1972)

Russell, C. T.: The New Creation. Bible Students Committee for Africa, Illinois (1998).

Southern, E. Music of Black Americans. W. W. Norton \& Company, New York (1971).

Senday, A.: Music in the Social and Religious Life of Antiquity. Fair Leigh Dickson University Press, Cranbury NJ. (1971).

Swami Rama: Living with Himalayan Masters. Himalayan Inst of Yoga Science \& Philosophy, Honesdde (1978)

Swami Prabhupada: A Second Chance. The Bhaktivedanta Book Trust, London (1991).

The Holy Bible, New International Version New York:Harrap Collins Publishers

Watch Tower Bible and Tract Society: When Some one you Love dies. A Brochure of Jehovah's Witness, New York (2000). 